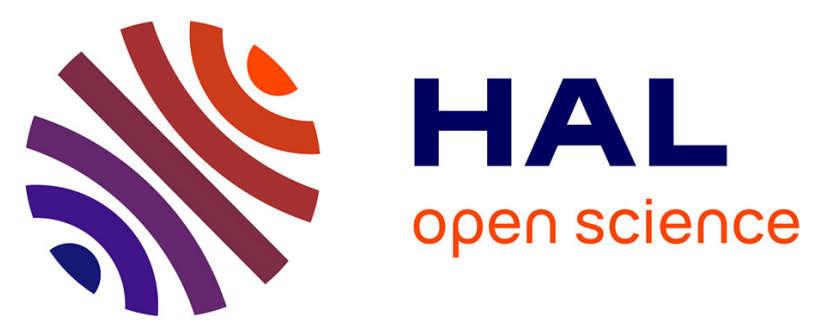

\title{
Soil moisture impact on lab measured reflectance of bare soils in the optical domain $[0.4-15 \mu \mathrm{M}]$
} Audrey Lesaignoux, Sophie Fabre, Xavier Briottet, Albert Olioso

\section{To cite this version:}

Audrey Lesaignoux, Sophie Fabre, Xavier Briottet, Albert Olioso. Soil moisture impact on lab measured reflectance of bare soils in the optical domain [0.4-15 $\mu \mathrm{M}]$. IGARSS 2009, Jul 2009, Cape Town, South Africa. 10.1109/IGARSS.2009.5417807 . hal-02758005

\section{HAL Id: hal-02758005 https://hal.inrae.fr/hal-02758005}

Submitted on 31 May 2021

HAL is a multi-disciplinary open access archive for the deposit and dissemination of scientific research documents, whether they are published or not. The documents may come from teaching and research institutions in France or abroad, or from public or private research centers.
L'archive ouverte pluridisciplinaire HAL, est destinée au dépôt et à la diffusion de documents scientifiques de niveau recherche, publiés ou non, émanant des établissements d'enseignement et de recherche français ou étrangers, des laboratoires publics ou privés. 


\title{
SOIL MOISTURE IMPACT ON LAB MEASURED REFLECTANCE OF BARE SOILS IN THE OPTICAL DOMAIN [0.4 - $15 \mu \mathrm{M}]$
}

\author{
Audrey Lesaignoux ${ }^{1,3, *}$, Sophie Fabre ${ }^{1}$, Xavier Briottet ${ }^{1}$, Albert Olioso ${ }^{2}$ \\ ${ }^{1}$ ONERA-DOTA, BP74025, 2 avenue Edouard Belin, 31055 Toulouse Cedex, France - \\ (Audrey.Lesaignoux, Sophie.Fabre, Xavier.Briottet)@ onera.fr \\ ${ }^{2}$ INRA, Site Agroparc domaine St-Paul, 84914 Avignon Cedex 9, France - olioso@avignon.inra.fr \\ ${ }^{3}$ Université de Toulouse, ISAE, 10 avenue Edouard Belin, 31055 Toulouse, France
}

\begin{abstract}
The purpose of this paper is to analyse the impact of surface soil moisture on spectral reflectance in the optical domain $[0.4-15 \mu \mathrm{m}]$. This work is based on lab spectral reflectance measurements of many bare soils at different moisture contents. Firstly, a classification of bare soil samples is performed according to their spectral signatures: five classes are then defined. Secondly, the soil moisture content impact on spectral signatures is analysed. In the [0.4 $-15 \mu \mathrm{m}]$ domain, measurements exhibit, for all the samples, a decreasing of the reflectance level with an increasing of moisture content. These measurements give information on absorption peaks related to soil mineral components like hydroxyl, carbonate, and quartz. Thus, analysis of our lab measurements indicates that soil moisture impact on spectral reflectance depends of studied spectral domain. These measurements may improve existing data bases, and will be used in a processing chain to estimate the soil moisture content (cases of bare soil and/or sparse vegetation) in the optical domain $[0.4-12 \mu \mathrm{m}]$ by using airborne hyperspectral imaging.
\end{abstract}

Index Terms - spectral reflectance, bare soils, soil moisture content, solar and thermal domain, laboratory measurements

\section{INTRODUCTION}

Knowledge of soil moisture content (SMC) is significant for many applications like trafficability after flood, ground atmosphere exchanges and plant good health,... Remote sensing data (optical to radar) have several advantages in comparison to in situ methods for monitoring SMC, like better temporal and spatial coverages. Moreover, hyperspectral data composed by numerous and contiguous spectral bands provide the most detailed information. Thus, the opportunity of using such technique to retrieve the SMC is investigated.

Soil optical properties, spectral reflectance and emissivity, are usually studied in the solar $[0.4-2.5 \mu \mathrm{m}]$ and thermal $[3-15 \mu \mathrm{m}]$ domain, and SMC characterisation from optical properties is more studied in the solar domain. In the $[0.4-15 \mu \mathrm{m}]$, mainly of approaches have been validated by lab measurements.

First works [1] have been performed in 1925 with lab measurements of spectral reflectance of bare soils at different moisture contents in the $[0.4-2.5 \mu \mathrm{m}]$. This study showed a decreasing of reflectance level with an increasing of SMC due to a darkening of soil color. Later, other lab measurements of bare soils [6] have confirmed this result, and have been mainly used to develop soil moisture estimation's approaches from spectral reflectance [8] [7] [13] [4].

In the infrared thermal domain [3-15 $\mu \mathrm{m}]$, few works have been realised from optical properties [11] [12] and soil moisture impact have been studied only in the long wavelength infrared (LWIR) [8-15 $\mu \mathrm{m}]$ domain [9] with spectral emissivity.

Consequently, there are not enough information in the thermal domain, and no measurement covering at once solar and thermal domains. So, we propose to build a database of spectral reflectance of bare soils in $[0.4-15 \mu \mathrm{m}]$ depending on SMC. This is the reason for having purchased lab measurements.

In this paper, the details of the experiment setup both for spectral reflectance and moisture content measurements are explained in section 2. The measurements are presented and analyzed in section 3. Finally, conclusions are given in section 4 .

\section{METHODS AND MEASUREMENTS}

Lab measurements of spectral reflectance of bare soils at different moisture contents have been purchased in August 2008 at ONERA Toulouse (France). About thirty natural soil samples, covering different ranges of composition (clay, limestone, sandy) and coloration, have been collected over eight locations in France.

\subsection{Measurement of moisture content sample}


Soil samples are put in petri-dishes and humidified until saturation. Drying process is obtained by in lab oven dry. Samples are dried to obtain five or six levels of moisture contents, which are estimated with the gravimetric method [4]. Soil moisture content SMC (\%) is computed according to the following relation:

$$
S M C=\frac{m_{W}-m_{D}}{m_{W}} \times 100
$$

where $m_{W}=$ weight of the wet sample, $m_{D}=$ weight of the dry sample estimated from the weight of the sample after a 24 hours drying period in oven at $60^{\circ} \mathrm{C}$, assuming that the residual soil moisture content was $2 \%$ [10].

\subsection{Measurement of spectral reflectances}

Concerning reflectance measurements, respectively biconical and directional hemispherical spectral reflectance data over $[0.4-2.5 \mu \mathrm{m}]$ and $[3-15 \mu \mathrm{m}]$ wavelength region are acquired using ASD (Analytical Spectral Device) Fieldspec Pro with an accuracy of $\Delta \lambda \pm 1 \mathrm{~nm}$, and Bruker Equinox 55 spectroradiometer with an error inferior at $3 \%$. So, kind of measurement is different following the waveband. We could not use an integral sphere on soil sample with the ASD.

In solar domain [0.4 - $2.5 \mu \mathrm{m}]$, ASD with about $10 \mathrm{~nm}$ spectral resolution is installed in a dark room laboratory. The soil samples are uniformly illuminated by a solar lamp with $15^{\circ}$ incidence, which spectral behavior is close to the spectral sun shape in the reflective domain. The measurements are performed at Nadir, and the $10^{\circ}$ field of view spectroradiometer is positioned vertically at a distance such that the observed surface is in agreement with the one of the Bruker spectrometer. Instrument calibration is performed with a spectralon lambertian references.

In thermal domain $[3-15 \mu \mathrm{m}]$, spectral reflectances are directly measured with a Fourier Transform InfraRed (FTIR) instrument (Bruker). An Infragold integral sphere is used from $2 \mu \mathrm{m}$ to $15 \mu \mathrm{m}$ with a spectral resolution better than $0.5 \mathrm{~cm}^{-1}$. Instrument calibration is achieved using an Infragold diffuse reference twice per day.

\section{RESULTS}

The spectral reflectances of bare soil's samples are measured at different moisture contents (about 50\% to 2\%). Therefore, more than three hundred spectral signatures are measured and analysed from the visible (VIS) [0.4 -0.8 $\mu \mathrm{m}]$, near and shortwave infrared (NSWIR) $[0.8-2.5 \mu \mathrm{m}]$, medium wavelength infrared (MWIR) $[3-5 \mu \mathrm{m}]$, and to the long wavelength infrared (LWIR) $[8-15 \mu \mathrm{m}]$ domains. We suggest first an analysis of dry samples spectra to determine an informal soil classification from spectra behaviour, and then a study of soil moisture content impact on spectra.

\subsection{Soil classification}

In VIS domain, three reflectance spectra classes are determined from previous works [3]: spectra weakly concave with low-level (T1V); spectra that is not particularly convex with high level (T2V); and spectra concave then convex with predominant level that is not particularly high (T3V). Spectra's T1V indicates that soil is composed by predominant organic matter, whereas $\mathrm{T} 2 \mathrm{~V}$ is typical of fullness's soil in lime but weak in iron oxide, then T3V appears for fullness's soil in iron oxide.

In NSWIR domain, presence of absorption peaks of hydroxyl $\left(\mathrm{OH}^{-}\right.$) at $1.4 \mu \mathrm{m}, 1.9 \mu \mathrm{m}$ and $2.2 \mu \mathrm{m}$ is the principal common characteristic for all the samples. And so we consider that there is only one type of spectra behaviour (TNS) for all the samples in NSWIR domain.

In MWIR domain, we are considering two types of spectra in this waveband: spectra bell-shaped (T1M) and spectra with two lobes (T2M).

In LWIR domain, most of minerals have typical minimum of emissivity. This minimum (or maximum of reflectance) is known like Reststrahlen band [11]. Presence of quartz $\left(\mathrm{S}_{i} \mathrm{O}_{2}\right)$ in soils, shows on reflectance spectra a strong Reststrahlen band between $8 \mu \mathrm{m}$ and $10 \mu \mathrm{m}$, whose the true location depends on amount of silica, and a weak Reststrahlen band between $12.2 \mu \mathrm{m}$ and $13 \mu \mathrm{m}$. Carbonates $\left(\mathrm{CO}_{3}^{2-}\right)$ are usually Reststrahlen bands between $6 \mu \mathrm{m}$ and $8 \mu \mathrm{m}$. However, secondary bands can exist, as an other band of carbonates at $11.3 \mu \mathrm{m}$. Finally, for our soil classification we are considering three types of spectra in LWIR: spectra with strong and weak Reststrahlen bands of quartz (T1L); T1L plus spectra with weak secondary Reststrahlen bands of carbonates (T2L); and spectra with strong secondary Reststrahlen bands of carbonates (T3L).

A first validation is performed according to soil coloration. Indeed, soil coloration is mainly due to mineral composition. For examples, a fullness's soil in iron oxide provides a soil coloration which tend toward red, whereas a white soil has as mainly component calcareous (carbonates). Soils classified by groups are compared to hue values of soils coloration by using Munsell color system (http://www.applepainter.com/). We observe a coherence between groups and hue values. In the next, it will be interesting to validate our classification by means of chemical analysis.

\subsection{Impact of soil moisture content}

From this classification, impact of soil moisture on spectral reflectance is studied.

In VIS, level of reflectance decreases when SMC increases for all types of soil (T1V, T2V and T3V) and spectra level deviation between dry and saturated sample is inferior to 
0.13 for all the samples. Furthermore, absorption peaks of iron $\left(\mathrm{Fe}^{2+}\right)$ existing in spectra $\mathrm{T} 3 \mathrm{~V}$, not seem very sensitive to moisture content (Figure 1, up and left).

In NSWIR, as demonstrated by previous works [1] [7] [4], level of reflectance reduces (inferior to 0.3), and depth of absorption peaks of hydroxyl $\left(\mathrm{OH}^{-}\right)$, at $1.4 \mu \mathrm{m}$ and 1.9 $\mu \mathrm{m}$, increase and widen with SMC (Figure 1, up and right). On the other hand, we noted loss of absorption peaks of the hydroxyl $\left(\mathrm{OH}^{-}\right.$) at $2.2 \mu \mathrm{m}$, because this peak is not linked to water but to other minerals.

In thermal domain $[3-15 \mu \mathrm{m}]$, as solar domain, increase of SMC involves decrease of reflectance level as described by Mira et al. [9] for emissivity, and furthermore, absorption peaks detection is almost impossible if SMC is upper $20 \%$ (Figure 1, down). In MWIR, carbonates and silicates (quartz) absorption peaks are lowered when SMC increases. This observation is better underlined in the spectra type T2M than T1M. In LWIR, SMC impact on Reststrahlen bands of quartz and carbonates. Spectra level deviation is higher in MWIR (inferior at 0.17) than in LWIR domain (inferior at 0.05 ), and so it's more difficult to study impact of soil moisture content in LWIR domain.
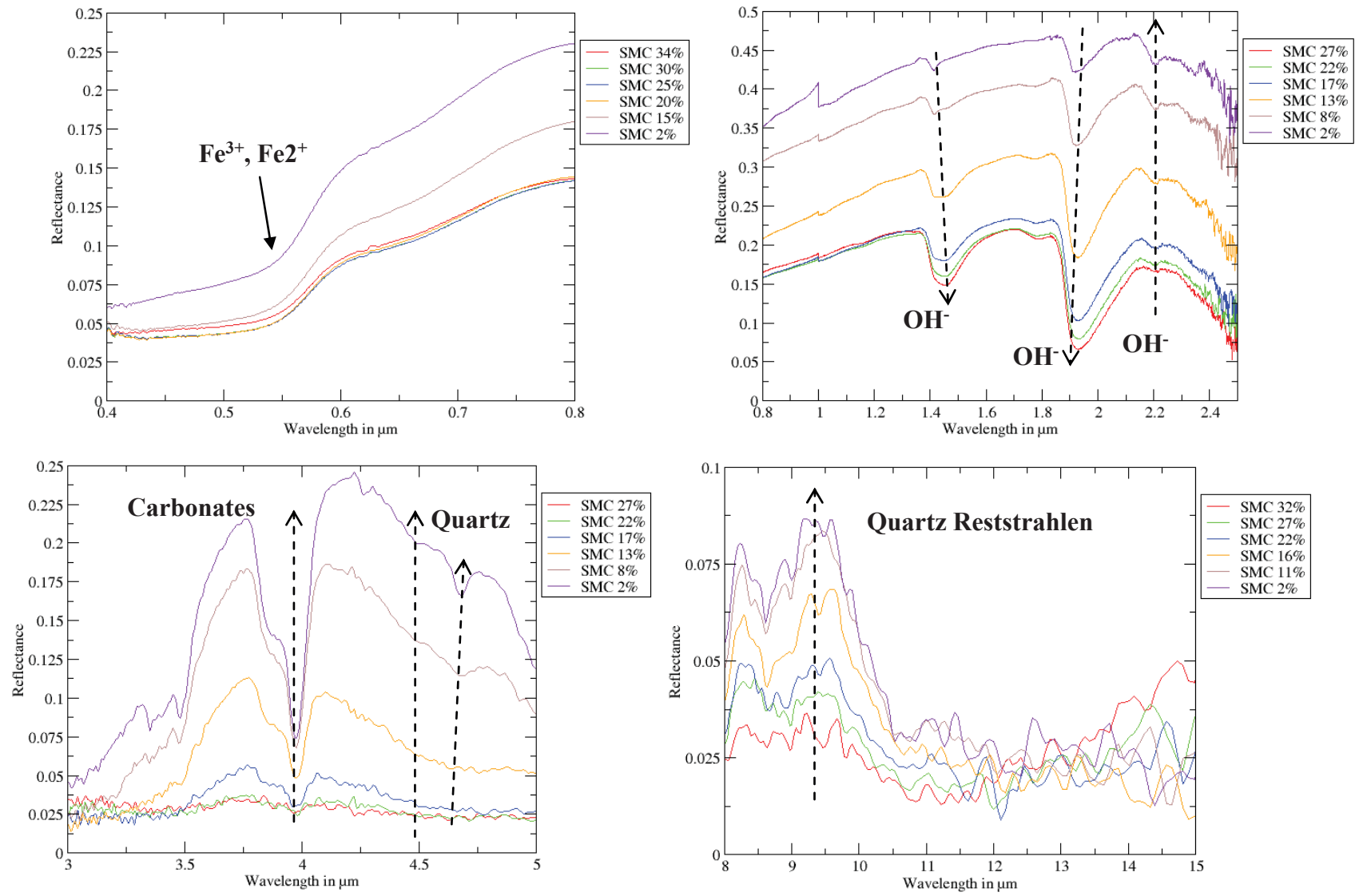

Figure 1. Impact of SMC in T3V (up, left), TNS (up, right), T2M (down, left) and T1L (down, right) reflectance spectra measurements

\section{CONCLUSIONS}

We dispose of a new database, composed of spectral reflectance of bare soils related to SMC in $[0.4-15 \mu \mathrm{m}]$. Therefore, laboratory measurements of bare soils show that an increase of SMC involves: a reduction of reflectance level in optical domain (mean of maximum reflectance deviation inferior to 0.3 ); a growth of depth and spreading absorption peaks of hydroxyl $\left(\mathrm{OH}^{-}\right)$, linked to water $\left(\mathrm{H}_{2} \mathrm{O}\right.$ ), at $1.4 \mu \mathrm{m}$ and $1.9 \mu \mathrm{m}$; a diminution of depth absorption peaks of minerals in NSWIR and MWIR wavebands; and a decrease of Reststrahlen bands of quartz and carbonates in LWIR.

This work has permitted us to better understand the soil moisture impact, and measurements will be used in a processing chain to estimate the SMC in the optical domain $[0.4-15 \mu \mathrm{m}]$, and to develop an empirical model 
of spectral reflectance of bare soil at different moisture contents.

\section{REFERENCES}

[1] Angström, A. (1925). The albedo of various surfaces of ground. Geografiska Annali, 7, pp. 323-327

[2] Clark, R. N. (1995). Reflectance spectra. American Geophysical Union, pp. 178-188

[3] Courault, D., Girard, M.C., \& Escadafal, R. (1988). Modélisation de la couleur des sols par télédetection. Actes $d u 4^{e}$ Coll. Int. Signatures spectrales d'objets en télédétection, Aussois, 357-362

[4] Haubrock, S., Chabrillat, S., Lemmnitz, C., \& Kaufmann, H. (2008). Surface soil moisture quantification models from reflectance data under field conditions. International Journal of Remote Sensing, Vol. 29, 1, pp. 3-29

[5] Khanna, S., Palacios-Orueta, A., Whiting, M.L., Ustin, S.L., Riaño, D., \& Litago, J. (2007). Development of Angle Indexes for Soil Moisture Estimation, Dry Matter Detection and Landcover Discrimination. Remote Sensing of Environment, 109, pp. $154-165$

[6] Liu, W., Baret, F., Gu, X.F., Tong, Q., Zheng, L., \& Zhang, B. (2002). Relating soil surface moisture to reflectance. Remote Sensing of Environment, vol. 81, pp. 238-246

[7] Liu, W., Baret, F., Gu, X., Tong, Q., Zheng, L., \& Zhang, B. (2003). Evaluation of methods for soil surface moisture estimation from reflectance data. International Journal of Remote Sensing, 24, pp. 2069-2083

[8] Lobell, D., \& Asner, G. (2002). Moisture Effects on Soil Reflectance. Soil Sciences American Journal, 66, pp. 722-727

[9] Mira, M., Valor, E., Boluda, R., Caselles, V., \& Coll, C. (2007). Influence of soil water content on the thermal infrared emissivity of bare soils: implication for land surface temperature determination. Journal of Geophysical Research, Vol. 112, F04003

[10] Peters, J. (2000). On-Farm Moisture Testing of Corn Silage. Focus on Forage, vol 2, nº

[11] Salisbury, J.W., \& D'aria, D.M. (1992). Emissivity of terrestrial materials in the $8-14 \mu \mathrm{m}$ atmospheric window. Remote Sensing of Environment, vol. 42, pp. 83-106

[12] Salisbury, J.W., \& D'aria, D.M. (1994). Emissivity of terrestrial materials in the $3-5 \mu \mathrm{m}$ atmospheric window. Remote Sensing of Environment, vol. 47, pp. 345-361

[13] Whiting, M.L., Li, L., \& Ustin, S.L. (2003). Predicting water content using Gaussian model on soil spectra. Remote Sensing of Environment, vol. 89, pp. 535-552 